International Journal of Scholarly Papers for Media and Communications

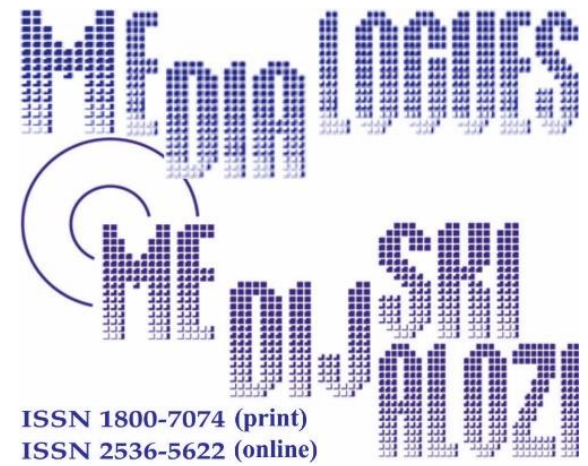

Bedi, K., Varga, M. (2021), „Visual Perception and Attitudes of Students Toward the Role and Importance of Photography - Students' Creative and Artistic Photographic Works Through Project - Based Learning", Media Dialogues / Medijski dijalozi, Vol. 14, No. 3, pp. 23-34.

\title{
Visual Perception and Attitudes of Students Toward the Role and Importance of Photography - Students' Creative and Artistic Photographic Works Through Project - Based Learning
}

\author{
KRUNOSLAV BEDI, \\ School of Civil Engineering, Art and Craft, \\ Cakovec, Croatia, \\ MATIJA VARGA \\ University of Zagreb, Faculty of Teacher Education, \\ Zagreb, Croatia
}

\begin{tabular}{|c|c|}
\hline$A \boldsymbol{R} \boldsymbol{T} \boldsymbol{C} \boldsymbol{L} \boldsymbol{E}$ & Received: January 25, 2021 / Revised from: February 23, 2021 \\
$\boldsymbol{I} \boldsymbol{N} \boldsymbol{F} \boldsymbol{O}$ & Accepted: March 25, 2021 / Available online: July 15, 2021 \\
\hline DOI & doi.org/10.14254/1800-7074/14-3/2 \\
\hline
\end{tabular}




\section{ABSTRACT}

The objective of the paper-and the investigation behind itwas to recognize the importance of photography in the visual perception in the project-based learning process in the third-grade students of a secondary school course. We live in the photography visual domination epoch and photography itself is an inevitable element of the visual distinction or even identification. In line with that, the paper presented the (best) photographs taken by students (Media Technician course) to have been awarded at various public contests. The second part of the paper presents the investigation into the perce tion and attitudes of the students as to the role and importance of photog-raphy i.e. into the level of the visual and CS literacy of students when the use of photography is implied.

KEYWORDS: Photography, Visual Communication, Visual Identification, Visual Sense, Visual Perception, Virtual Identity, Project-Based Learning (PBL).

\section{INTRODUCTION}

Although it seems to be quite a contemporary invention, an image of an object on a light-sensitive emulsion layered background dates as far back as in the year of 1822. In the course of the whole 19th century, this technology had been going through a series of improvements and innovations. The very development of photography went hand in hand with the change in the perception of the human reality and it was because the photography primarily influ- enced the existing painting art/perception as it offered a more real image of reality. Besides that, the future was yet to show that photography influenced (and has influenced) the contemporary means of visual communication, for example, the film, the TV, electronic media, the Internet etc.

There are millions of new photographs published on Facebook and Instagram daily. In terms of the contemporary education of designers and media technicians in the fields of either graphic design or electronic media design, it is of a crucial importance for a student to be acquainted with the photography media. The photographic image is one of the basic materials for a contemporary graphic designer to work with, regardless of the image being an original or a replica/reproduction. The designers and media technicians of today usually work with ready-made photographic products or order them from professional photographers but yet have to be acquainted with both the technical aspects (the types and features of various cameras and photo materials) and the technological ones, namely the process of making photographs. This is why the education process has to provide the students the access to all the respective knowledge so that they could learn the principles of composing photographs and how to use lenses and to develop watching skills. Besides that, it is as well important to learn and get acquainted to the light/shade relations and to understand the importance of "the critical moment" while shooting particular motifs. 
Finally, along with all the creative possibilities at disposal, it is important to get to know the genres of the photographic records - the studio photography, portraits, landscapes, acts and still life etc. What is as well inevitable in the educational process is the unconceivable array possibilities offered by the computer manipulation of photographs. It is due to the new digital technology used as well at shooting and at the post-processing of the record. A subsequent change and intervention into the recorded material can change both one's experience of a photograph and the expression of the world that the photograph reflects.

\section{VISUAL COMMUNICATION}

Visual methods, such as photography, offer children ways to address issues relevant to them [3]. Photographers use cameras as a means with which they influence the awareness and consciousness of other people and this makes photography being more important today than ever before. A fragment of the world, once extracted from space and time and frozen by photographing may express a general feature of the whole world in the way that makes us impossible to watch the world with the same perception we used to have. Each and every minute, millions of photographs are being uploaded to social networks and web sites. They inform us on the most hidden corners of the world and they are more powerful than words. Despite the processes of homogenization, these photographs do not reveal a world of single meaning but a world of a miraculous diversity instead. The visual design is therefore an essential predictor of the learners' cumulative impressions of, and preferences for, an elearning tool (Sánchez-Franco et al., 2013).

Every photographer hopes for some coincidental life circumstances and skills that would lead them to the pedestal of a distinguished photographer. The photographs that have marked history or a moment in history either tell more than a thousand speeches made by a thousand of politicians or can initiate more action than thousands of humanitarians. The most famous photographs are not recorded in our minds as the photographs of politicians. It would rather be Sharbat Gula ("Afghan Girl") is a photograph by journalist Steve Mc Curry) or the photograph of raising the flag on Iwo Jima taken by Joe Rosenthal.

Visual communication is a powerful means of transferring thoughts and ideas and, moreover, the power of critical and visual evaluation of the presented information has become a key skill in the electronic environment. 


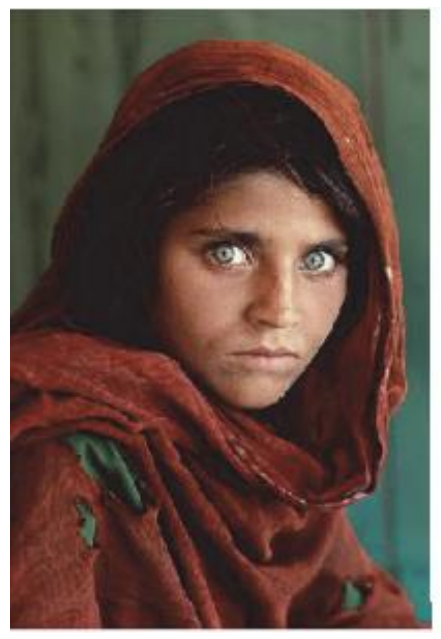

Picture 1. Afghan Girl

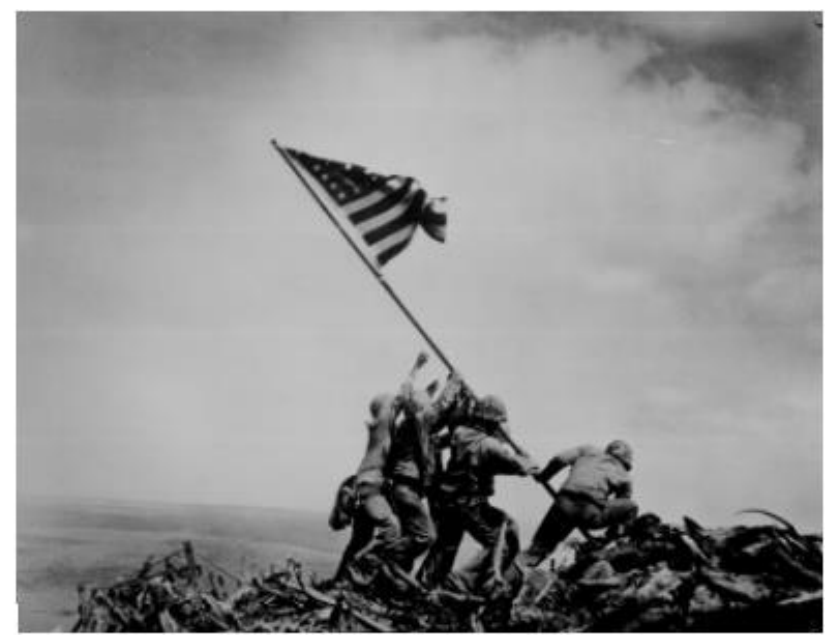

Picture 2. Raising the Flag on Iwo Jima

\section{STUDENTS' DESIGN AND VISUAL COMMUNICATION IN THE REALM OF PHOTOGRAPHY}

Visual communication is an interdisciplinary field. What the visual communication design education aims to develop in students is the competence in design towards creating an effective visual language and communicating with it. Students are exposed to inter-disciplinary visual communication platforms adapting to the current developments in information technology and changing aesthetic values (4).

In visual communication, individuals perceive and interpret the visual images in their surroundings according to their previous experiences and repertoire of visual codes. The perception of visual images requires a reading process that is similar to the reading and interpretation of written texts (1).

In the course of the school year, the group consisting of 16 third grade students of the Media Technician secondary school course were assigned with several photographic tasks and took part in several public contests with the photographs they had taken. Prior to that, in the earlier years of the course, the students had to learn the basics of digital photography. Their photographic works were made within the curricula of two subjects, "Media Photography" and "Creative Photography. Depending on particular contest propositions, the students had to include the scanning or photograph taking processes, cutting out details and adjustment of elements, designing backgrounds and colour correction. Depending again on particular contest propositions, the elements could be imported into Adobe Photoshop and processed. The project of making photographs was based on project based learning (PBL) and on constructivist paradigm. Photographs significantly enhance one's experience and knowledge. 
Photographs mirror life and it is thus an advantage if one is able to watch them. Photographs teach people, informs them, photographs shape, entertain, challenge, shock and encourage communication. An overview follows of the students' works awarded at various public contests in the course of the school year 2015/2016.

Table 1. Awarded students' works
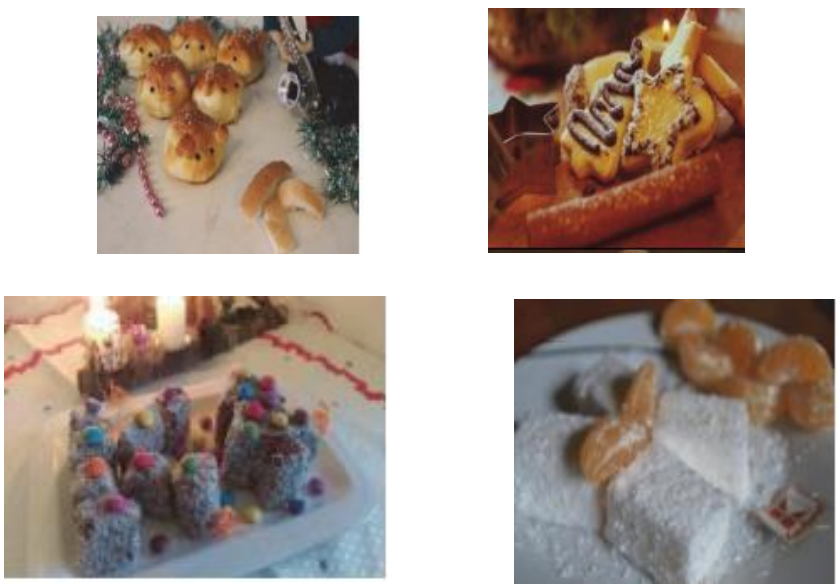

The photographs awarded at Kaufland's contest - Christmas Photo Contest

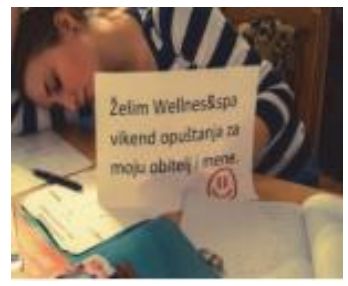

The photograph awarded at Nov@TV contest

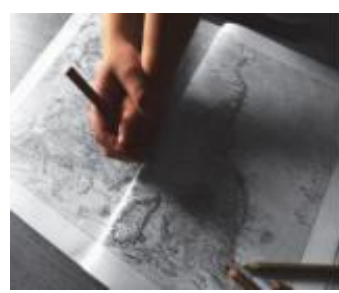

The photograph awarded at "Paint the World" contest

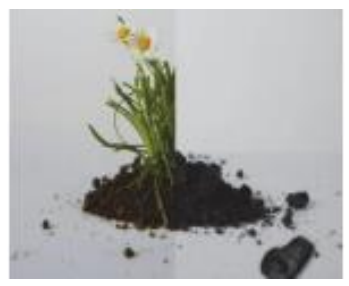

The photograph awarded at Click - creative contest "Give an Idea For a Better Atmosphere"

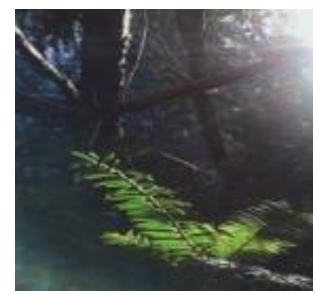

"A Fairy Tale", photograph from the "The Nature of my Homeland Međimurje" contest 


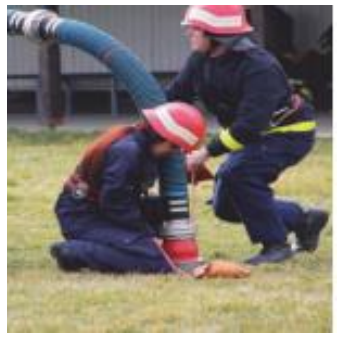

The photograph awarded at "Young People and Firefighting" contest

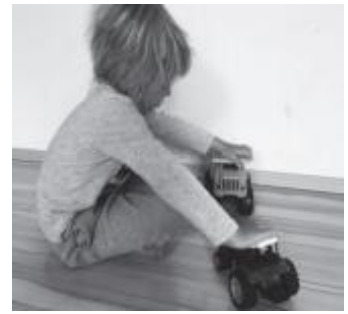

The photograph awarded at "Young People for Human Rights" contest

In which way the students experience the work on photographs is most properly told through one of descriptions of the process of making a photograph within the theme of "Tolerance, Lack of Violence and Peaceful Dispute Resolving".

A student (D.S.) says: "By means of the photograph, I wanted to express trust, peace of mind and tranquility. I used the colour of blue to convey my thoughts, the colour that as well dissolves into its lighter shades and symbolizes understanding. Only one blue drop suffices for tolerance, lack of violence and peaceful problem resolving. The photograph was taken in the following way: I put some water into a container and then let a drop of blue paint from an eyedropper into the water and the paint dissolved into various shades and lines. To give the photograph even more magic, I pressed the release button while the drop was falling into the water. It took me at least 3 hours to make the photograph. Although the blue colour was my first preoccupation, I as well tried to cope with the theme by means of polychrome paints, but the process was too demanding. The effort invested in the photograph has well paid off."

\section{RESEARCH METHODS}

The perception of photography as an important factor in the multimedia technologies of today is important for the approach to learning. The awarded students' works were made in the course of one school year and within the curricula of two subjects - Media Photography and Creative Photography; this work and the research were, in turn, aimed at the mutual detection and the importance of the role of photography in the contemporary media. The objective of the research is to present the obtained data on the perception and attitudes of the students as to the role and importance of photography i.e. on the level of the visual and CS literacy of students when the use of photography is implied.

The research was conducted by the survey method whereas the results are shown in pie charts. The research was done in the May of 2016 via the Internet, i.e. online. 
Likert scale was used for the surveyed to express the level of their subjective agreement with the given statements. The scale comprised four levels, (1-strongly disagree; 2- disagree; 3- agree; 4- strongly agree).

The survey was taken among the students of School of Building and Crafts C̆akovec. There was the total of 104 students, out of which 62 females and 42 males. The life age span of the surveyed ranged from 15 to 20 .

\section{RESEARCH RESULTS}

The aim of the survey was to get feedback on:

- Your gender is...?

- Photography is the technique of digital or chemical recording of everyday life scenes on a layer of material sensitive to the light it is exposed to.

- Photography plays important role in the contemporary media.

- Photography helps and/or may help with e-learning?

- Do you consider the interest in photography to be in an increase lately?

- Do you think that photography teamed with a text helps with learning/elearning?

- In my case, the use of photographs when doing homework, writing papers and seminars, making presentations etc. is frequent one.

- Do you think that photography draws more attention than other content that is presented on a screen (text, animation, video...)?

- Do you think that photography in the teaching process has a good perspective in a long run?

- Do you consider photography to be inevitable in the media space of today?

- Do you agree with the statement that a photograph is worth a thousand words?

- The virtual surroundings photography (digital photography) is of the same value as the classic photography made on the light-sensitive paper?

- Attractive photographs should be used in presentations because it makes the presentations better. graphs

- The audience will be more interested if they are offered/presented nice photo-

- A quality photograph is determined by the number of pixels.

- The colour photography is more attractive and more interesting than the black and white photography

- Do you agree with the statement that a quality photograph can be taken by a professional photographer only?

- Amateur photographs are less valuable than those taken by an educat- ed professional photographer. 
- Do you agree with the statement that a quality photograph requires a quality camera with larger resolution?

- Newspaper photographs are less valuable than photographs printed on a top quality paper and in a high quality magazine.

- Do you think that a top quality photograph always needs to be post- processed by some of the professional software for picture processing?

The most interesting answers to the most interesting answers are as follows:

- The students acknowledge a great importance of photography in the contemporary media (Figure 1);

- more than a half of the surveyed consider photography to be important for learning (Figure 2)

- and that it is inevitable in the media space of today (Figure 3).

$-$

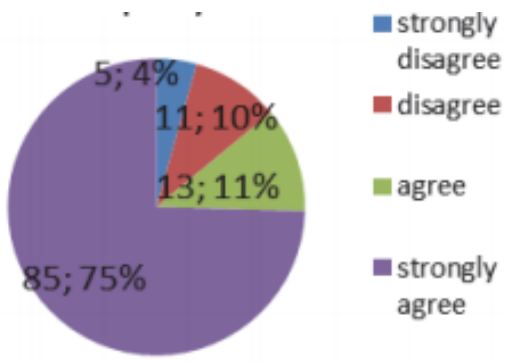

Figure 1. Photography plays important role in the contemporary media

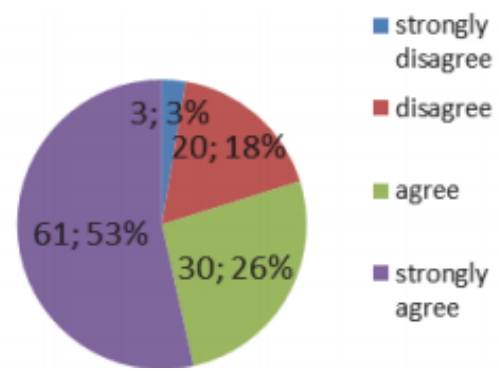

Figure 2. Do you think that photography teamed with a text helps with learning/elearning? 


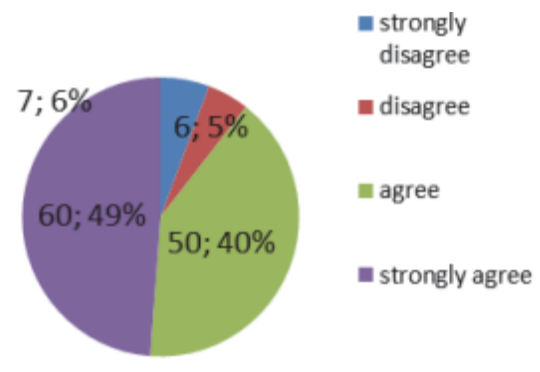

Figure 3. Do you consider photography to be inevitable in the media space of today?

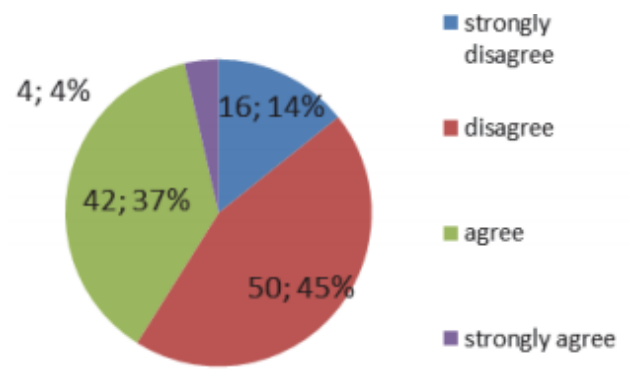

Figure 4. The virtual surroundings photography (digital photography) is of the same value as the classic photography made on the light-sensitive paper?

Despite the media space digital photography revolution (Figure 4), the photography on paper is still highly rated (Figure 5).

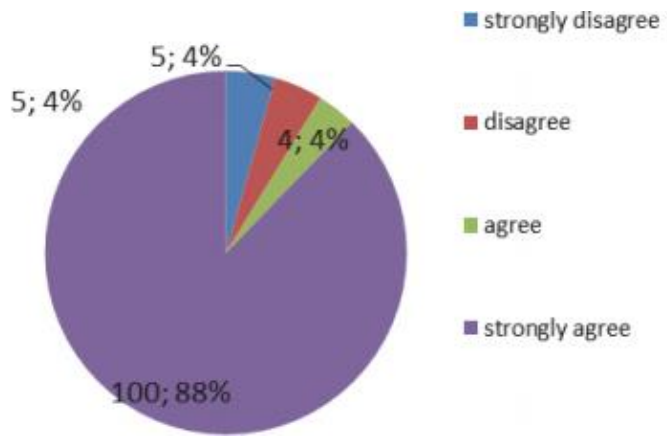

Figure 5. Attractive photographs should be used in presentations because it makes the presentations better.

In terms of importance, the perception of the attractiveness (the artistic impression) of photographs in presentations turns to be twice as favourable as the influence 
of the technical features of photographs the resolution, the number of pixels (Figure $6)$.

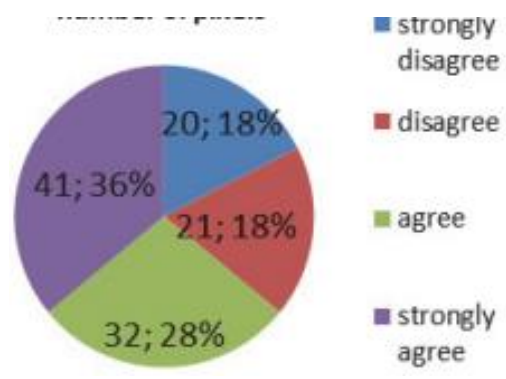

Figure 6. A quality photograph is determined by the number of pixels

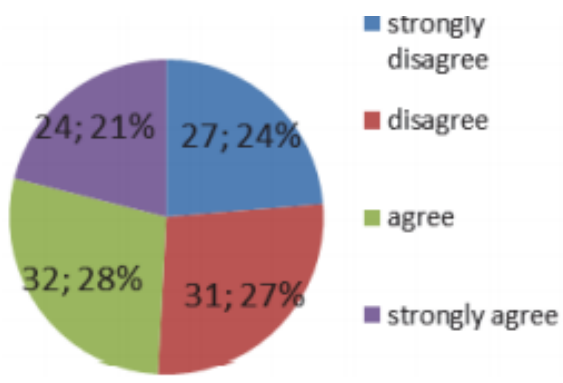

Figure 7. The colour photography is more attractive and more interesting than the black and white photography

The students' perception that quality photographs require both knowledge and skill can be seen from the data in Figure 8 where more than two-thirds of the surveyed consider the quality to be the product of professional work.

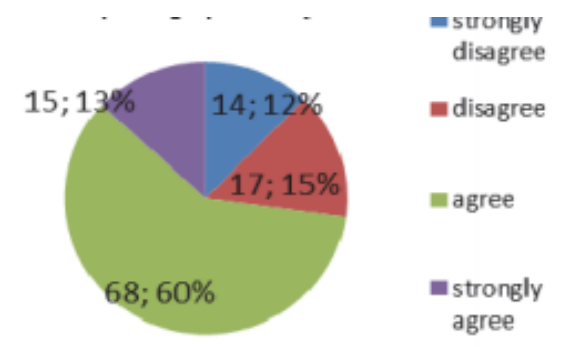

Figure 8. Do you agree with the statement that a quality photograph can be taken by a professional photographer only? 
Students as well think that quality equipment is needed for taking quality photographs (Figure 9), but the post-processing by a professional software is a necessity though it is not an imperative and it is not always needed (Figure 10).

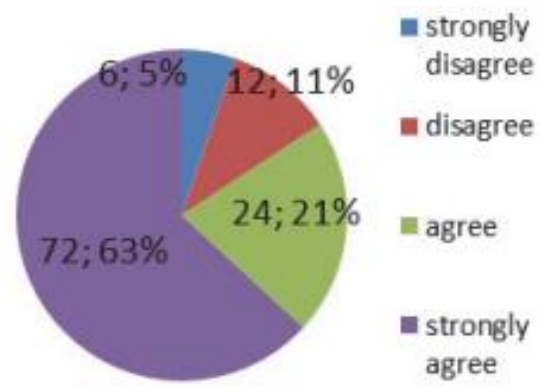

Figure 9. Do you agree with the statement that a quality photograph requires a quality camera with larger resolution?

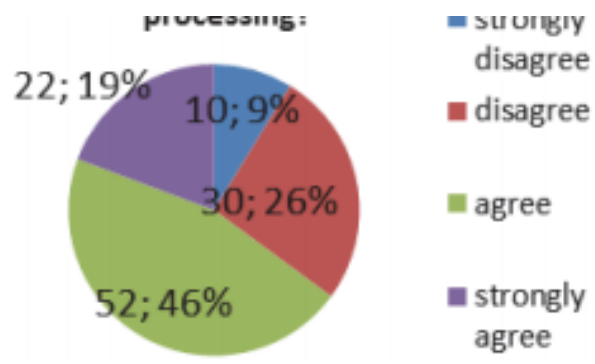

Figure 10. Do you think that a top quality photograph always needs to be post-processed by some of the professional software for picture processing?

Conclusion Humans have always felt a need for recording some life events, some movements and shapes wanting simultaneously to permanently keep their images. Various things have been used for this purpose in the course of history. The digital and computing technologies that developed late in the 20th century have since provided for a revolutionary change of the character of photography thus completely shifting it from the real world of things into the world of digital bytes. So, it is possible today already to store photographs on CDs, high capacity DVDs, memory cards, computer hard disks and other media using digital recording technology. Nowadays, when the market has been flooded by digital cameras, the digital photography has been replacing or, in most of cases, has already replaced the analogue one. The research done on a population of children showed that students follow the contemporary trends as to the visual perception of photography and that they see the importance of photography in the media culture of today. 
The understanding of the effective visual communication increases the level of CS literacy and therefore indirectly influences the communication process and its effects.

\section{REFERENCES}

Uyan Dur, B.I. (2014), "Reflection of Anatolian Culture in Poster Design", Procedia - Social and Behavioral Sciences, Vol. 122, pp. 230-235.

Sánchez-Franco, M.J., Villarejo-Ramos, A.F., Peral-Peral, B., Buitrago-Esquinas, E. M., Roldán, J.L. (2013), “Users' Perception of Visual Design and the Usefulness of A Web-based Educational Tool", Procedia - Social and Behavioral Sciences, Vol. 93, pp. 1916-1921.

Eskelinen, K. (2012), "Children'sVisual Art and Creating Through Photographs", Procedia - Social and Behavioral Sciences, Vol. 45, pp. 168-177.

Adiloglu, F. (2011), "Visual communication: design studio education through working the process", Procedia - Social and Behavioral Sciences, Vol. 28, pp. 982991

http://en.wikipedia.org/wiki/Afghan_Girl

http://en.wikipedia.org/wiki/Raising_the_Flag_on_Iwo_Jima\#/media/File:WW2_I wo_J ima_flag_raising.jpg 